\title{
ANALISA DAN PERANCANGAN APLIKASI SISTEM PENDUKUNG PENGAMBILAN KEPUTUSAN PEMINATAN JURUSAN BERBASIS ANDROID DEVELOPMENT TOOLS (ADT) DENGAN PENERAPAN METODE NAIVE BAYES DAN TEOREMA BAYES
}

\author{
Devri Suherdi \\ Politeknik Ganesha Medan \\ Jl. Veteran No 190 Pasar VI Manunggal \\ devrisuherdi10@gmail.com
}

\begin{abstract}
Abstrak- Penentuan peminatan jurusan ini dilakukan dengan menggunakan metode naïve baye, Naïve Bayes merupakan metode Bayesian Learning yang paling cepat dan sederhan. Penentuan peminatan dilakukan dengan menghitungpeluang terhadap mata kuliah dasar yang wajib lulus bagi mahasiswa/I Aplikasi peminatan jurusan berbasis android ini dirancang menggunakan gabungan bahasa pemograman Java SDK dan Android SDK dengan menggunakan eclips sebagai editor program yang di bunding dalam satu aplikasi yaitu Android Development Tools ( ADT ). Aplikasi ini sudah biasa digunakan untuk penentuan peminatan jurusan. Nilai KHS sebagai input dasar penentuan peminatan. Namun aplikasi ini masih perlu pengembangan lebih lanjut agar dapat di jalankan dalam jaringan atau internet sehingga dapat di akses kapan pun dan dimana Pun yang dibutuhkan oleh pengguna.
\end{abstract}

Keywords - Peminatan Jurusan, Naïve Bayes, ADT.

\section{PENDAHULUAN}

Dalam k Beberapa Penelitian yang berhubungan dengan penelitian ini sebagai berikut :

Ebranda A.W (2010,p,10) dengan sebuah penelitian dengan judul " Penerapan Metode Naïve Bayes untuk system klasifikasi sms ada smartphone android " yang menguraikan tentang aplikasi SMS spam yang memiliki fitur yang dapat menggolongkan atau mengklasifikasikan suatu SMS mana yang spam dan mana yang bukan spamsecara otomatis dengan adanya diterapkan metode naïve bayes untuk melakukan proses klasifikasi SMS dengan tingkat ke akuratan yang tinggi sehingga spam SMS dapat teridentifikasi dengan baik.

Sembiring A. Sani (2014,Vol IV,1) dengan sebuah penelitian tentang " Penerapan Metode Bayes sebagai keputusan untuk menentukan tingkatan kualitas buah jeruk " dengan menggunakan metode bayes, dapat dihitung [probalitas kualitas buah jeruk berdasarkan pe

Rhitungan dari bobot kriteria masing - masing yang telah ditentukan terlebih dahulu, dengan perhitungan probabilitas kualitas buah jeruk tersebut dapat ditentukan apakah buah jeruk yang diteliti berkualitas tinggi atau rendah.Teori Bayes ini cocok diterapkan dalam DSS.

Hermawan (2009,p-1-8) yang membahas tentang alat bantu peminatan SMK dan menguraikan tentang system pendukung keputusan yang akan mengolah data dengan metode bayes dan akan menampilkan keluaran berupa jurusan alternative yang sesuai dengan potensi siswa/I itu sendiri..

\section{KERANGKA PEMIKIRAN}

Komunikasi data adalah pertukaran data antara dua perangkat atau lebih melalui media transmisi misalnya seperti kabel. Untuk bisa terjadinya komunikasi data, perangkat harus saling berkomunikasi atau terhubung menjadi sebuah bagian dari sistem komunikasi, yang terdiri atas kombinasi dari peralatan fisik atau keras (hardware) dan perangkat aplikasi atau program (software)[1].

Peminatan jurusan adalah suatu kegiatan yang dilakukan setiap akhir tahun pembelajaran, dimana setiap mahasiswa/I mulai menentukan pilihan peminatan jurusan sebagai keahlian khusus mahasiswa untuk setiap jurusannya. Sedangkan peminatan jurusan paa perguruan tinggi khususnya di jurusan teknik informatika ini ditentukan sesuai dengan nilai kartu hasil studi ( KHS ) untuk mata kuliah tertentu dari semester $1-6$

Metode naïve bayes ini merupakan metode Bayesian Learning yang paling cepat dan sederhana, dan bayes merupakan pendekatan statistic untuk melakukan inferensi induksi pada persoalan klasifikasi Pembahasan pertama adalah tentang konsep dasar dan definisi pada teorema bayes, kemudian menggunakan teorema ini untuk melakukan klasifikasi dalam data mining.

Sedangkan kerangka pemikiran untuk penerapan metode Naïve Bayes pada system pendukung pengambilan keputusan peminatan jurusan berbasis ADT ini dapat di lihat pada gambar 1. 


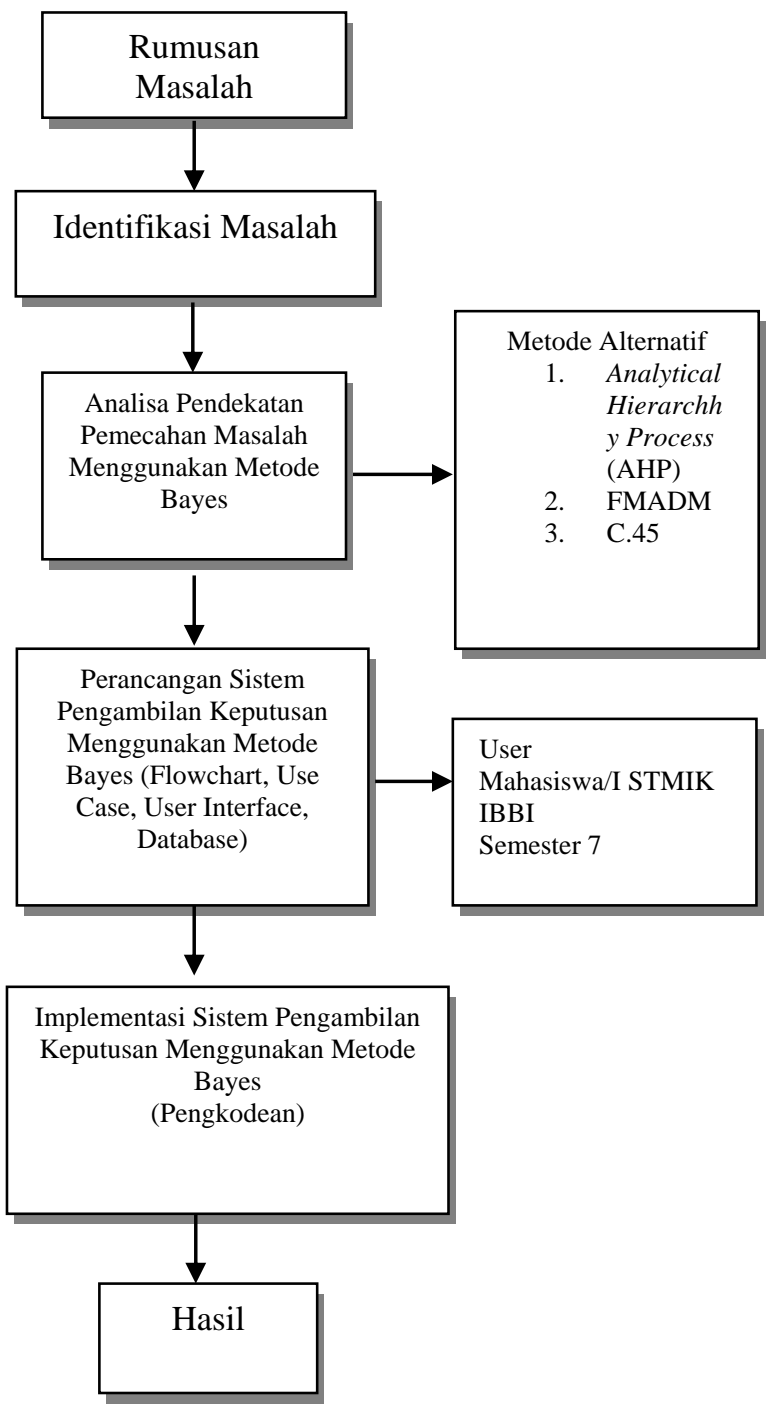

Gbr.1 Kerangka Pikir Penelitian

\section{METODOLOGI PENELITIAN}

Analisis kebutuhan berfokus pada penggunaan pendekatan utnuk pengembangan system peminatan jurusan yang menggunakam Metode Bayes dimana implementasi system ini ditereapkan di perguruan tinggi dan di uju coba untuk mengetahui kemampuan dari system yang telah dibuat

Ada dua teknik pengumpulan data yaitu pengumpulan data Data Primer dan pengumpulan data Skunder.

A. Analisis Contoh Kasus Peminatan Penerapan Metode Nä̈ve Bayes

Misalnya seorang mahasiswa yang sudah selesai mengikuti perkuliahan semester dan memiliki niali kartu Hasil Studi ( kHS ) untuk 23 mata kuliah yang digunakan sebagai dasar penentuan peminatan jurusan
TABEL I

NILAI KARTU HASIL STUDI

\begin{tabular}{|c|c|c|}
\hline & Mata Kuliah & Nilai \\
\hline 1 & Fisika Elektronik & B \\
\hline 2 & Jaringan Komputer & A \\
\hline 3 & Prakt. Jaringan Komputer & B \\
\hline 4 & Pemrograman web & B \\
\hline 5 & Prakt. Pemrograman web & B \\
\hline 6 & Teknologi Open source & B \\
\hline 7 & Prakt. Teknologi Open source & B \\
\hline 8 & Kalkulus-1 & B \\
\hline 9 & Kalkulus-II & B \\
\hline 10 & Multimedia & B \\
\hline 11 & Prakt. Multimedia & B \\
\hline 12 & Sistem Basis Data & B \\
\hline 13 & Prakt. Sistem Basis Data & B \\
\hline 14 & Grafika Komputer & B \\
\hline 15 & Prakt. Grafika Komputer & B \\
\hline 16 & Statistika Dan Probabilitas & $\mathrm{C}$ \\
\hline 17 & Arsitektur Dan Organisasi Komputer & A \\
\hline 18 & Assembler Dan Sistem Microprosesor & $\mathrm{C}$ \\
\hline 19 & Prakt. Assembler Dan Sistem Microprosesor & B \\
\hline 20 & Kecerdasan Buatan & B \\
\hline 21 & Prakt. Kecerdasan Buatan & $\mathrm{C}$ \\
\hline 22 & Perantaraan Dan Peripheral & A \\
\hline 23 & Prakt. Perantaraan Dan Peripheral & $\mathrm{C}$ \\
\hline
\end{tabular}

Berdasarkan nilai Kartu Hasil Studi ( KHS ) diatas maka dapat dilakukan pembobotan nilai per mata kuliah menggunakan metode bayes, rumus yang digunakan adalah sebagai berikut:

Nilai i $=$ Nilai ij $\{$ krit ij $\}$

Di mana : Nilai $\mathrm{i}=$ Nilai Bobot per Mata Kuliah

Nilai ij = Tingkat Nilai Hasil KHS di atas Nilai Dasar

Kritij = Nilai Bobot Mata Kuliah Dasar

Misalnya untuk peminatan Jaringan, di mana Nilai KHS mata kuliah Fisika Elektronik adalah B, sedangkan nilai dasar adalah $\mathrm{C}$, sedangkan nilai bobot dasar adalah 0,14. Maka nilai bobot mata kuliah tersebuit adalah sebagai berikut :

Nilai $\mathrm{ij}=2$, di mana $\mathrm{C}$ adalah nilai dasar, maka nilai $\mathrm{C}=1, \mathrm{~B}=2, \mathrm{~A}=3$, selain itu $=0$.

Krit ij $=0,14$

Nilai $\mathrm{i}=2 \mathrm{X} 0,14=\mathbf{0 , 2 8}$ 
Sesuai dengan perhitungan di atas maka pembobotan nilai untuk setiap peminatan jurusan adalah sebagai berikut :

1. Pembobotan Nilai Peminatan Jaringan

Bobot nilai per mata kuliah sesuai dengan Kartu Hasil Mahasiswa (KHS) untuk peminatan jaringan dapat dilihat pada Gambar 3.3 Grafik Peminatan Jaringan Menjelaskan Pembobotan nilai mata kuliah dalam analisa studi kasus peminatan

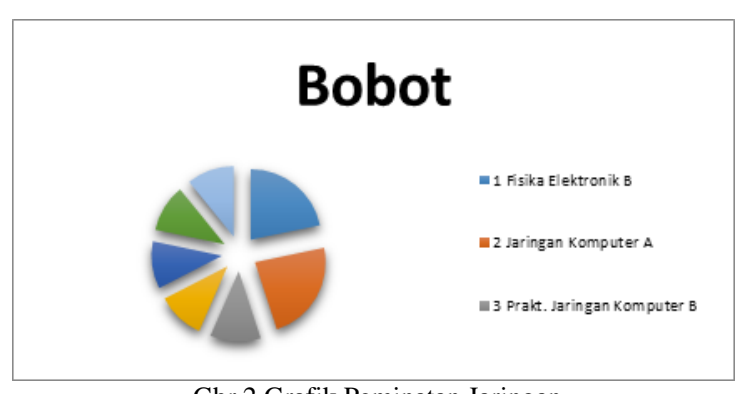

Gbr.2 Grafik Peminatan Jaringan

2. Pembobotan Nilai Peminatan Multimedia

Bobot nilai per mata kuliah sesuai dengan Kartu Hasil Mahasiswa (KHS) untuk peminatan Multimedia dapat dilihat pada Gambar 3

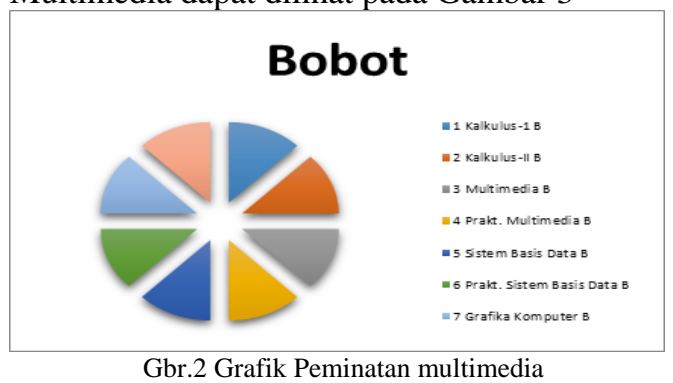

3. Pembobotan Nilai Peminatan Robotika

Bobot nilai per mata kuliah sesuai dengan Kartu Hasil Mahasiswa (KHS) untuk peminatan Multimedia dapat dilihat pada Gambar 3.5 Grafik Peminatan Robotik Menjelaskan Pembobotan nilai mata kuliah dalam analisa studi kasus peminatan

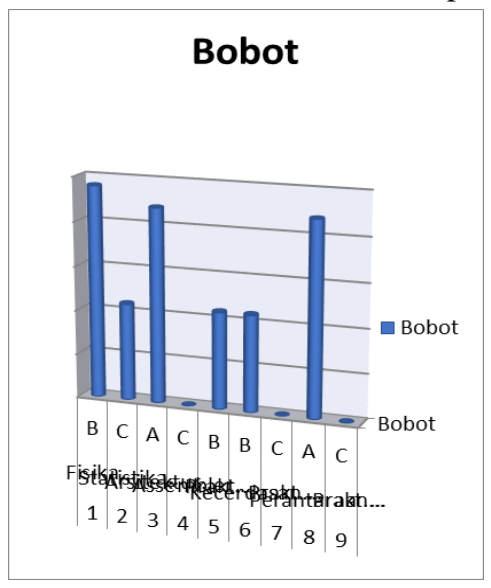

Gbr.3 Grafik Peminatan robotika
Berdasarkan hasil perhitungan total nilai bobot untuk setiap peminatan jurusan menggunakan metode Bayes di atas, maka dapat disimpulkan bahwa mahasiswa tersebut lulus untuk ketiga peminatan jurusan tersebut, baik untuk Peminatan Jaringan $(1,19)$, Peminatan Multimedia $(1,00)$ dan Peminatan Robotika $(1,01)$ karena total nilai bobot ketiganya di atas atau sama dengan satu. Namun sesuai dengan aturan yang telah ditentukan di atas, di mana mahasiswa akan disarankan untuk memilih peminatan dengan total nilai bobot terbesar, maka mahasiswa tersebut disarankan masuk Peminatan Jaringan.

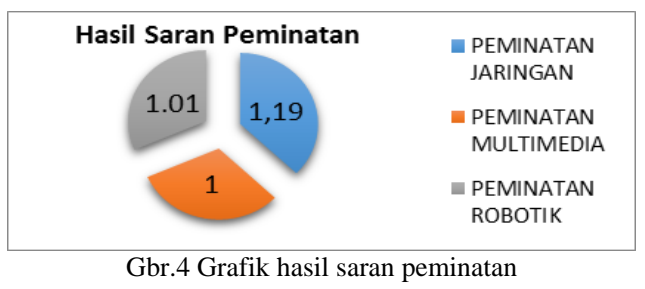

A. Perancangan Proses

Perancangan proses digunakan untuk menggambarkan rancangan sistem yang akan dibuat. Proses kerja sistem peminatan jurusan menggunakan metode Naïve Bayes dan Teorema Bayes Android ini dirancang menggunakan :

1) Flowchart : Flowchart proses kerja sistem peminatan jurusan menggunakan metode Bayes ini dapat dilihat pada Gambar 5

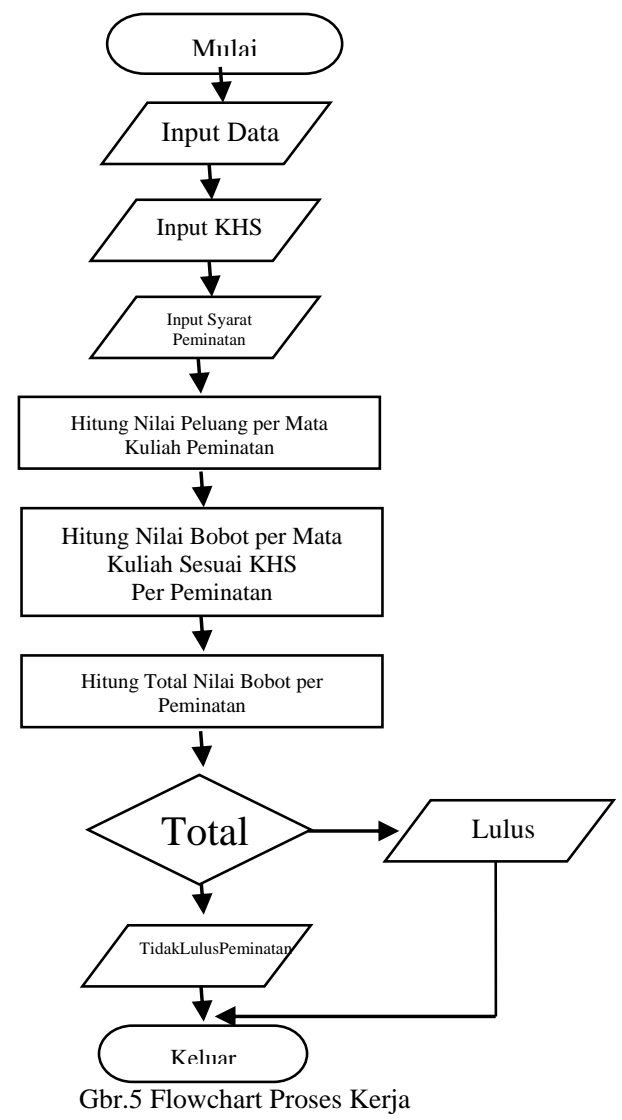




\section{HASIL DAN PEMBAHASAN}

A. Menguji Proses Pemilihan Emulator Android

Sebelum menjalankan program berbasis android maka terlebih dahulu pengguna harus melakukan setting emulator android yang digunakan dalam hal ini digunakan Android versi 4 (API4). Adapun langkahlangkahnya adalah sebagai berikut :

1. Download Android Emulator di develover.android.com/sdk/incex.html.

2. Lakukan proses instalasi, lalu jalankan SDK Manager.

Pilih aplikasi android mana yang akan diemulasikan, misalnya android versi 4 .

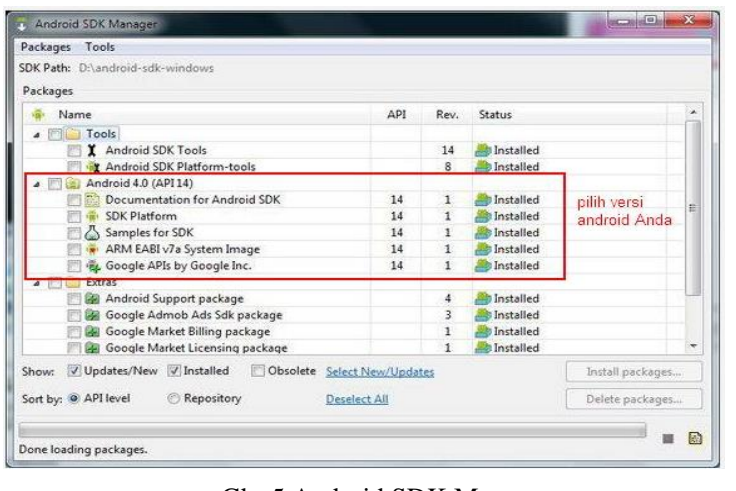

Gbr.5 Android SDK Manager

3. Setelah semua file ter-download, silakan buka AVDM (Android virtual Device Manager) dan buat sebuah device baru dengan menekan tombol New, hingga muncul tampilan Gambar 6

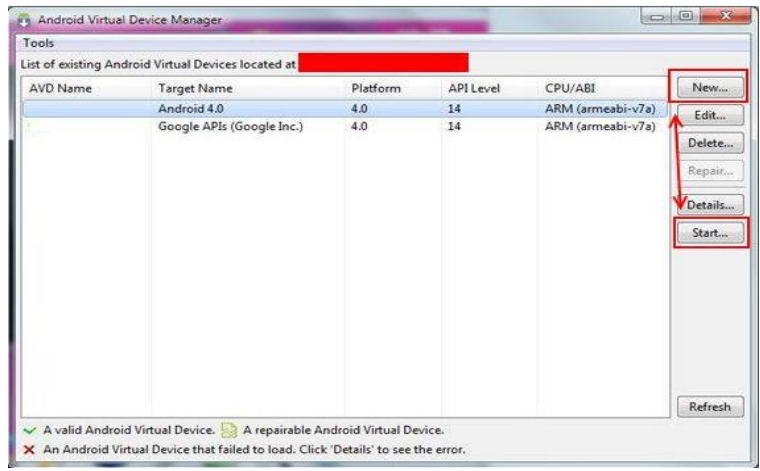

Gbr.6 Android virtual Devices Manager

\section{B. Pembahasan}

Berdasarkan proses pengujian terhadap sistem peminatan jurusan menggunakan metode Bayes berbasis Android di atas, hasil setiap pengujian dikumpulkan sehingga membentuk data-data seperti terlihat pada gambar 7 .

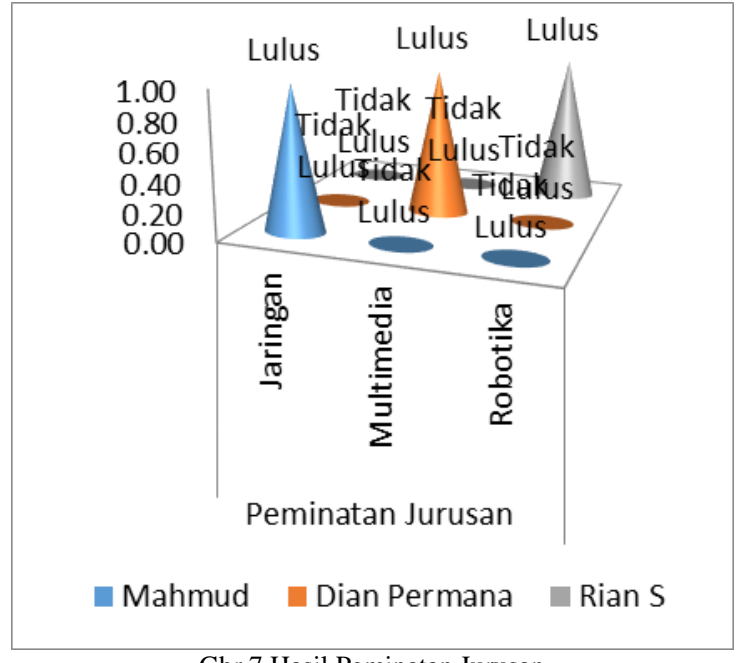

Gbr.7 Hasil Peminatan Jurusan

\section{KESIMPULAN DAN SARAN}

\section{A. Kesimpulan}

Sesuai dengan penelitian yang dilakukan, maka penulis mengambil kesimpulan sebagai berikut :

1. Dalam mengambil keputusan, sistem ini dirancang Berbasis android Development tools ( ADT ) dengan penerapan Metode Naïve Bayes

2. Proses aplikasi dijalankan berdasarkan penentuan peminatan jurusan sudah dapat dilakukan dengan tepat, baik untuk peminatan jaringan, multimedia dan robotika dengan menghitung total nilai bobot per peminatan berdasarkan nilai KHS mahasiswa.

3. Sistem yang digunakan dalam menjalankan aplikasi ini hanya dapat digunakan untuk melakukan penentuan peminatan jurusan untuk satu mahasiswa sekali proses, sehingga akam membutuhkan waktu yang lama untuk pengolahan datanya jika mahasiswa yang akan melakukan peminatan jurusan cukup banyak. Dan Aplikasi ini masih menggunakan sistem single user sehingga belum bisa dijalankan dalam bentuk jaringan apapun.

\section{B. Saran}

Adapun saran yang ingin penulis berikan berdasarkan hasil penelitian ini sebagai berikut :

1. Aplikasi ini dapat dikembangkan dengan melakukan perbandingan metode Bayes dengan metode pengambilan keputusan lainnya, seperti Analytical Hierarchhy Process (AHP), Profile Matching dan lain sebagainya.

2. Aplikasi perlu dikembangkan lagi agar bisa dijalankan dalam sistem berbasis jaringan internet, sehingga dapat diakses mahasiswa dimanapun dan kapanpun dibutuhkannya.

3. Aplikasi ini bisa juga dikembangkan agar dapat memproses data peminatan jurusan untuk beberapa mahasiswa sekaligus sehingga bisa menghemat waktu dalam pengolahan datanya. 


\section{REFERENSI}

[1] Ebranda A.W, 2010, Penerapan metode Naïve Bayes untuk sistem klasifikasi

sms pada smartphone android, Universitas Dia Nuswantoro, Semarang

[2] Sembiring A. Sani ,2014, Penerapan Metode Bayes sebagai keputusan untuk

menentukan tingkatan kualitas buah jeruk " dengan menggunakan metode bayes, Vol IV , 1 ,STMIK Budi Darma, Medan

[3] Hermawan W, 2009,aplikasi Bantu Peminatan SMK Menggunakan Metode Bayes, A11.2009.04690,Universitas Dia Nuswantoro, Semarang

[4] Ario dkk, 2009, Sistem Informasi SimulasiPemilihan Mata KuliahPeminatan Mahasiswa, p-1-8, STMIK GI MDP

[5] Variq, dkk, 2010, Sistem Tutor Cerdas Mengunakan Metode Bayesian Network, ITS November, Surabaya

[6] Swastina, L, 2013, Penerapan Algoritma C4.5 Untuk Penentuan Jurusan Mahasiswa, Vol 2 No 1, STMIK Indonesia, Banjarmasin

[7] Ariani, Dwi..Pepi, dkk, 2014, Sistem Pendukung Keputusan Pemilihan Jurusan SMK Menggunakan Neuro Fuzzy, ITS Surabaya

[8] Dito, 2013, Sistem Pendukung Keputusan Pemilihan Jalur Peminatan Program Studi Teknik Informatika, p.1-8,Univ. Dian Nuswantoro

[9] Putri SN, 2014, Sistem Pendukung Keputusan Seleksi Penerimaan Siswa Baru Menggunakan Metode Electre WP, p.1-14, Univ. Brawijaya, Malang

[10] Tobing, L. G, 2014, Sistem Pendukung Keputusan Pemilihan Jurusan Pada SMK N 1 Siatas Barita dengan Metode Simple Additive Weighting(SAW),Vol IV, STMIK Budi Darma, Medan

[11] Nuryanti, Dewi Lulu Yohanna, w. Kusuma Diah, 2008, Sistem Pendukung KeputusanMenggunakan Metode AHP Berbasis Web Untuk Menentukan Jurusan, Politeknik Caltek Riau, Pekanbaru - Riau

[12] Harison, 2013, Analisis Sistem Pendukung Keputusan Penentuan Konsentrasi Jurusan Teknik Mesin UNP Padang, Vol 1 No 1, Tekmoif, Institut Teknologi Padan, Padang

Devri Suherdi received his Master. in Eresha School IT, in 2015

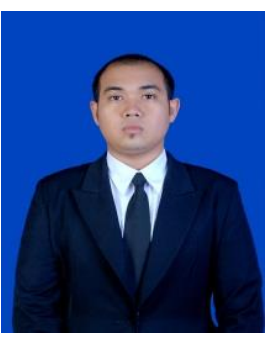

$\mathrm{He}$ was born in P.Brandan, Indonesia on the 10th of October 1987. He received his Bachelor of Tekhnic Informatic Engineer and graduated from Management of high school informatics and computer IBBI, in 2010.

His research interest has been primarily in the area of Businees Engineering, with Bayes method .Devri Suherdi works as a lecturer at Politeknik Ganesha, Medan, Indonesia,

for contact e-mail devrisuherdi10@gmail.com 